Research Article

\title{
The Design and Comparison of Central and Distributed Light Sensored Smart LED Lighting Systems
}

\author{
Mehmet Ali Özçelik (iD \\ Technical Science, Electric and Energy Department, Gaziantep University, Şehitkamil, 27310 Gaziantep, Turkey \\ Correspondence should be addressed to Mehmet Ali Özçelik; ozcelik@gantep.edu.tr
}

Received 26 December 2017; Revised 10 February 2018; Accepted 27 February 2018; Published 3 April 2018

Academic Editor: Mahmoud M. El-Nahass

Copyright ( 2018 Mehmet Ali Özçelik. This is an open access article distributed under the Creative Commons Attribution License, which permits unrestricted use, distribution, and reproduction in any medium, provided the original work is properly cited.

\begin{abstract}
There is a lack of published peer-reviewed research comparing the efficiencies of distributed versus central sensor-controlled LED lighting systems. This research proposes improving the smart illumination of a room with external fenestration using central and distributed light sensors. The optical and electrical measurements of the daylight have been made in the case where the light was not distributed evenly and not sufficient. Test results show that the proposed distributed light sensor illumination system has increased the efficiency by $28 \%$ when compared to the proposed central system. It has also been shown that the two tested systems are more cost-effective than common smart illumination systems.
\end{abstract}

\section{Introduction}

Energy-efficient resources are essential in today's world [1-3]. Petroleum- and coal-based conventional power plants are continuously spreading harmful gasses such as nitrogen dioxide and carbon dioxide that threaten the environment and human health [4]. The renewable energy resources emerge as an effective solution for increasing the need for clean energy [5]. Among renewable energy resources, solar energy is one of the promising ones providing major benefits, such as being environmentally friendly and being silent [6]. Studies show that the photovoltaic (PV) system can reduce release of one ton of carbon dioxide per kWh of electricity [7]. The modular structure of PV panels enables easy integration to energy-efficient buildings. Because such a modular structure can efficiently integrate electrical, electronic, and mechanical systems [8], the electrical energy used for illumination is equivalent to $20 \%$ of the total electrical energy production of the world $[9,10]$. For this reason, the energy demand for illumination obtained from renewable energy sources is essential in terms of pollution-free environment. In the USA, the UK, and China, at least $20 \%$ of the total electric power production from renewable energy sources has been targeted till 2020. Moreover, it is envisaged that renewables will contribute to over $50 \%$ by 2050 in some countries [11-13]. Light-emitting diode (LED) technologies have significantly lowered down the energy demand needed for illumination. Moreover, they are durable and environmentally friendly [14-17]. Energy efficiency, smart buildings, and green buildings have recently come to the foreground as some striking topics. Furthermore, an illumination control is usually designed according to the needs of spots in the buildings to decrease energy consumption $[18,19]$. With LED luminaires, it is possible to control the light output easily and accurately. Additionally, LED luminaires enable the flexible adaptation of a lighting system to its environment [20]. Artificial lighting accounts for a major fraction of global electrical energy consumption. In a typical office building, the energy consumed due to artificial lighting can be up to $40 \%$ of the total energy consumption [21]. As the need for the use of energy resources is increasing, the need for illumination control becomes essential.

Automatic or photoelectrically controlled lighting systems in the buildings can significantly reduce the lighting energy consumption down to as low as $50 \%[22,23]$. Some authors have proposed an illumination model-based method and algorithm for intelligent open-loop lighting control. Specifically, the simulation results were presented using a simplistic virtual room [24, 25]. A single light sensor-driven lighting system was made early by Rubinstein [26] and 
Peruffo et al. [27]. Distributed optimization algorithms for lighting control with daylight and occupancy adaptation were proposed in Caicedo and Pandharipande [28] and Lee and Kwon [29], under networking and information exchange constraints. Techniques such as daylight harvesting and automatic dimming control with wireless sensor, illumination balancing, Konnex Association Worldwide Standard for Home and Building Control (KNX), digital addressable lighting interface (DALI) standard, and stochastic hill climbing optimization are applied to lighting control [30, 31]. However, DALI and KNX which are used to add intelligence to buildings have higher costs as much as tens of thousands of dollars for the basic installation [14].

In smart lighting systems, the illumination level of the indoor environment can be determined by means of light sensors [32]. In these systems, the electrical information obtained from the sensors is converted into illumination knowledge [33]. The light information of the environment can be measured by a centrally located sensor or by placing more than one sensor in a distributed manner [34, 35]. By comparing the ambient light value measured by the sensors and the microprocessor system with the desired reference illumination value, the lighting levels of the LED luminaires can be increased or decreased to achieve the desired illumination rate. In this study, the efficiency and cost analysis of two different proposed smart LED architectures with the centralized and distributed sensor structure were performed in the $54 \mathrm{~m}^{2}$ classroom having two windows. The solution has been designed keeping in mind that low power, low consumption, and scalability are addressed. To the best of the author's knowledge, it is the first time to compare the central sensor and the distributed sensor smart LED lighting.

\section{Method}

2.1. The PV System, LED Illuminating System Set on the DC Grid and the Positioning of LED Panels. As the sunlight hits on PV cells, photovoltage and photocurrent act like a forward diode on a large surface. The current expression resulted from the sunlight hitting on the cell is given.

$I=I_{\mathrm{PH}}-I_{\mathrm{S}} \cdot\left\{\exp \left[\frac{q}{A \cdot k_{\mathrm{B}} \cdot T}\left(V+I \cdot R_{\mathrm{L}}\right)\right]-1\right\}-\frac{\left(V+I \cdot R_{\mathrm{S}}\right)}{R_{\mathrm{SH}}}$,

where $I_{\mathrm{PH}}$ is the photocurrent, $I_{\mathrm{S}}$ is the saturation current, $R_{\mathrm{L}}$ is the load resistance, $R_{\mathrm{S}}$ is the series equivalent circuit resistance, $R_{\mathrm{SH}}$ is the parallel equivalent circuit resistance, $V$ is the terminal voltage, $I$ is the load current, $A$ is the

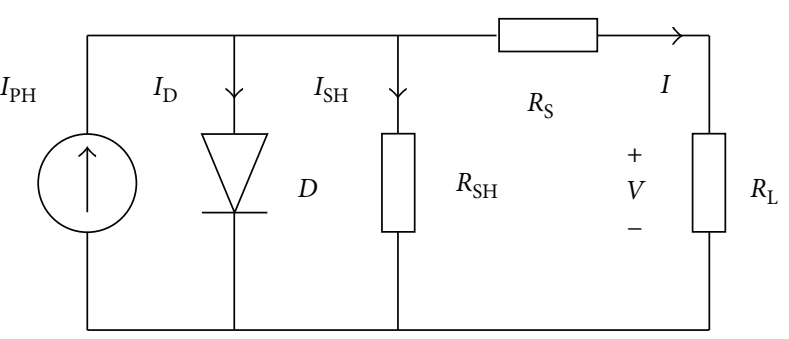

FIgURE 1: Equivalent circuit diagram for solar cell.

TABLE 1: Electrical parameters of the PV and the LED lighting systems.

\begin{tabular}{lc}
\hline Maximum power PV system & $390 \mathrm{~W}$ \\
Maximum current of PV system & $10.83 \mathrm{~A}$ \\
The maximum current and power of each of the & $1 \mathrm{~A} / 36 \mathrm{~W}$ \\
LED panel lamp & 8 \\
The number of LED lamps & $288 \mathrm{~W}$ \\
\hline
\end{tabular}

diode ideality factor, $k_{\mathrm{B}}$ is Boltzmann's constant, and $T$ is the temperature of the PV panel, respectively. As it is seen, photocurrent, saturation current, load resistance, series equivalent circuit resistance, parallel equivalent circuit resistance, terminal voltage, load current, diode ideality factor, Boltzman's constant, and temperature of the PV panel are denoted by $I_{\mathrm{PH}}, I_{\mathrm{S}}, R_{\mathrm{L}}, R \mathrm{~s}, R_{\mathrm{SH}}, V, I, A, k$, and $T$, respectively.

The equivalent circuit diagram of a solar cell is shown in Figure 1 [36].

In the smart LED lighting system, six PV panels are used and each panel is rated at $12 \mathrm{~V}$ and $65 \mathrm{~W}$. PV panels are connected in series and are parallel with PWM charge regulators to obtain $36 \mathrm{~V}$. Table 1 shows the electrical parameters of the PV and the LED lighting systems.

The lumens per watt $(\mathrm{lm} / \mathrm{W})$ of the LED lamps used in the lighting systems is 88 . The maximum luminous flux is 3200 lumen. The specifications of the room used in the experiment are as follows: (1) The room shape is rectangular having width $a=6 \mathrm{~m}$ and length $b=9 \mathrm{~m}^{2}$ ). The room height is $h=3 \mathrm{~m}^{3}$ ). The vertical distance between the working plane and the luminaire is $1.85 \mathrm{~m}$. Based on the EN 12464 lighting of indoor work places standard [37], the recommended classroom light level is 300 lux.

The LED distribution curve for the classroom illumination is shown in Figure 2.

Calculations of energy storage capacity are as follows:

$$
\begin{aligned}
& \text { Maximum daily power consumption }(\mathrm{MDPC})=\text { total LED panels power } \times \text { operation time }=288 \times 8=2304 \mathrm{Wh} \text {, } \\
& \text { Battery capacity }=\frac{\mathrm{MDPC}}{\text { charge controller ef ficiency } \times \text { depth discharge } \times \text { system voltage }}=\frac{2304}{0.9 \times 0.75 \times 36}=\cong 100 \mathrm{Ah} \text {. }
\end{aligned}
$$

When the battery efficiency is $80 \%$, the capacity value must be increased by $100-80=20 \%$. In this case, the required battery capacity is as follows: the required battery capacity $=100+100 \times 0.20=120$ Ah. 


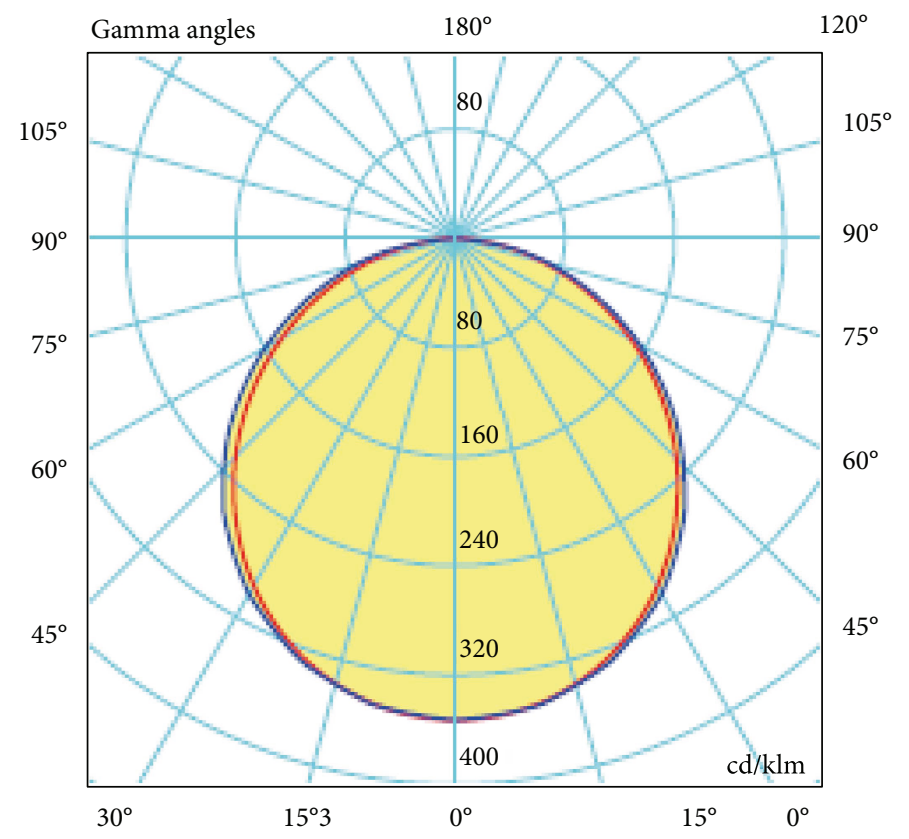

FIgURE 2: Light distribution curve for the classroom [38].

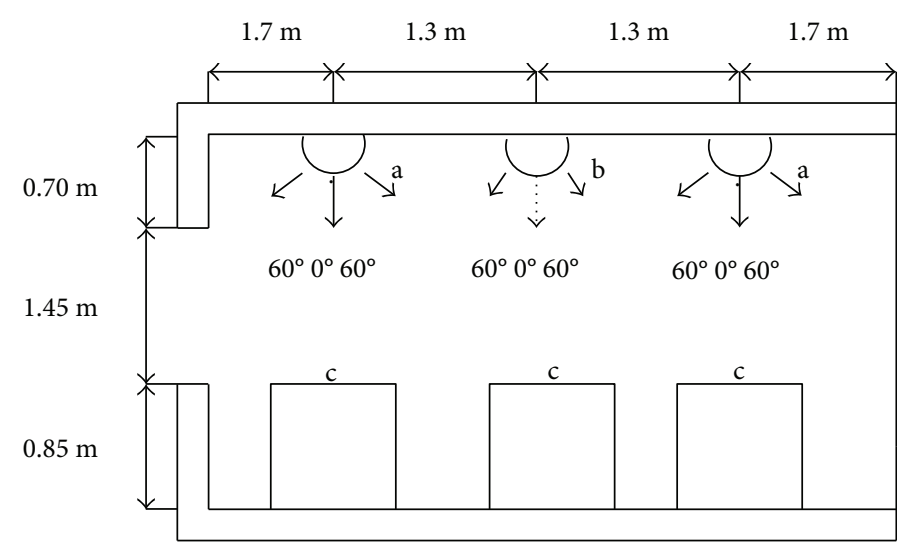

FIGURE 3: Locations of light sensors and illuminance meters: (a) light sensors of the distributed system, (b) light sensor of the central system, and (c) illuminance meters.

The algorithm designed for the illumination control system in this study is a closed loop. In the closed-loop system, the light sensors are installed on the ceiling where changes in illuminance are related to variations in illuminance on the work surface. In areas where either indirect or direct-indirect electrical lighting systems are used, the light sensor should be installed at a place that should not get direct light from luminaires [39]. The placement of the light sensors used in the distributed and central illumination systems together with the illuminance meters are given in Figure 3. The light sensors are placed 60 degrees so that they are not exposed to direct daylight or LED light.

A TEMT6000 Ambient Light Sensor is utilized in this work $[10,40]$. This sensor can measure incident illuminance up to 1000 lux with a peak sensitivity at around $580 \mathrm{~nm}$ with a spectral sensitivity curve adapted to match the human eye responsivity. The sensor output is an analog current information, converted to a variable voltage $(0-5 \mathrm{~V})$ that is read by the STM32F407 microcontroller through a $10 \mathrm{~K}$ resistor. The photocurrent and illuminance of the sensor are presented in Figure 4.

The sensor TEMT6000 is the wide angle of half sensitivity $\varphi= \pm 60^{\circ}$. Its relative radiant sensitivity and angular displacement are given in Figure 5. This device of the sensor is strictly linear between $\leq 10$ lux and $\geq 1000$ lux, and the typical photocurrent is specified for $50 \mu \mathrm{A}$ (at $100 \mathrm{~lx}$ ). The photocurrent $\left(I_{\mathrm{PCE}}\right)$ and illuminance equation of the TEMT6000 is given.

$$
\text { Illuminance }(\operatorname{lux})=\frac{1}{2} I_{\mathrm{PCE}}(\mu \mathrm{A}) \text {. }
$$

In the system where the ambient light sensors are used, the purpose is to adjust the LED illumination level to the desired one and thus to decrease power loss. In daylight- 


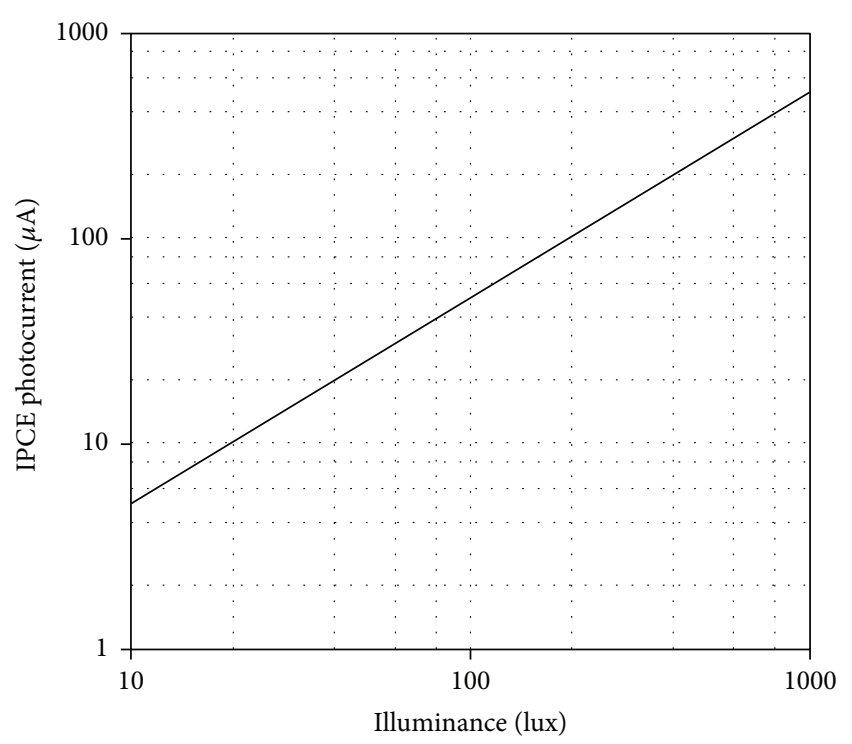

FIGURE 4: The relative photocurrent and illuminance of the TEMT6000 ambient light sensor [40].

exposed buildings and spaces, it can be realized that significant energy saving is achieved, which improves the quality of the visual environment and reduces the demand for electric illumination through the effective employment of automatic lighting controls [41, 42]. A light sensor with a wide spatial sensitivity mounted on the ceiling will have more difficulty during tracking the daylight when it receives more direct light from the window [43]. Also, the presence sensor was used. The reason for using the presence sensor is for the system to cut off energy to save energy and to reduce unnecessary power usage when there is no presence in a given environment for a certain time. The presence sensor's detection distance is $360^{\circ}, 32$ meters.

In the applied central and distributed sensored PV-based smart LED lighting system, an option for switching off the grid is available. The PV-based smart LED illuminating system view is shown in Figure 6. The block charts of the central and the distributed systems are illustrated in Figures 7 and 8, respectively. A direct current (DC) obtained from PV panel's LED lighting system using a DC-level dimming technique has been proposed and compared with distributed (zone) and central light sensor smart control systems. The smart illumination of the $54 \mathrm{~m}^{2}$ classroom having two windows, each $3.1 \mathrm{~m}$ long, has been implemented in a PV-equipped building. The lighting system has been designed for $36 \mathrm{~V}$ DC. To obtain this value, $12 \mathrm{~V}$ battery and PV panel groups have been used. The smart lighting system consists of $36 \mathrm{~W}$ over plaster LED panels designed to work with both PV system and grid. The windows are positioned at one side of the classroom which impede the homogeneous distribution of lighting the evening or in cloudy weathers. Hence, the control of the LED panels is carried out separately for the windows and the walls.

In the PV-based central sensor smart LED illuminating system, the block chart as shown in Figure 7 has been adjusted in such a way that, with the potentiometer connected to the TEMT6000 ambient light sensor, the ambient reference value can be obtained. The reference value is designed as 300 lux. The maximum rate of this reference for a classroom environment is 350 lux while the minimum value is 250 lux. These values are in the hysteresis range, and these values have been determined by users' preferences [10]. If the light knowledge taken from the ambient light sensor is less than the reference minimum limit, the volume of the light is increased. Similarly, both actions are performed by the proposed algorithm with the PWM method. The sensor light information is sent to the analog input of the STM32F407 microcontroller kit. The PV-based central sensor smart LED illuminating system block chart is shown Figure 7, The PWM control output over the optocoupler brings the illumination level of LED lamps to the required level by adjusting the duty cycle of MOSFETs.

The block chart of the PV-based distributed sensor smart LED illuminating system is shown in Figure 8. In the applied distributed sensored PV-based illuminating system, there exists an option for switching to grid connection.

With potentiometers 1 and 2 connected to the TEMT6000 light sensors, the reference lighting level of the environment can be adjusted. By adjusting PWM values that are produced based on the reference lighting level, thanks to the IRFP460 N-Channel Power MOSFETs, it is possible to control one by one the LED lighting level on the wall column and the window column separately. The reference lighting level depends on the user preference which is recommended as 300 lux for the classroom environment [15].

The right detection of the sensor points is important which affects the whole system performance. For example, when the system is exposed to direct sunlight or LED panel light, wrong feedbacks can be given to the control algorithm. Moreover, the same wrong feedbacks could be caused due to the shadows created by human or object motions [43]. For this reason, the sensors have been positioned close to the ceiling and in the mid points of LED illumination groups. At these points, the sensors will not be exposed to the LED panel, shadow lightings, and direct daylight. If the light knowledge taken from the ambient light sensors is below the reference minimum limit, the volume of the light is increased; in case the light knowledge is over the maximum reference limit, the light volume is decreased. The sensor light knowledge is sent to the analog input of the STM32F407 microcontroller kit. The PWM control output over the optocoupler brings the illumination level of LED lamps to the desired level by adjusting the duty cycle of MOSFETs. In the block structure seen in Figure 8 , if there exists solar irradiation or there is redundant power in battery groups, DC power, without requiring conversion into $\mathrm{AC}$, can meet the LED light energy. As shown in Figure 6, the ambient light sensors have been placed near the ceiling of the classroom. The lux voltage information obtained from the ambient sensors is sent to the microcontroller card's 32-bit analog input. The values obtained from here, in relation with the reference value by the algorithm, regulates the duty cycle of both MOSFETs. Thus, by adjusting the lighting levels of the LED panels, the desired level of the lighting of the environment 


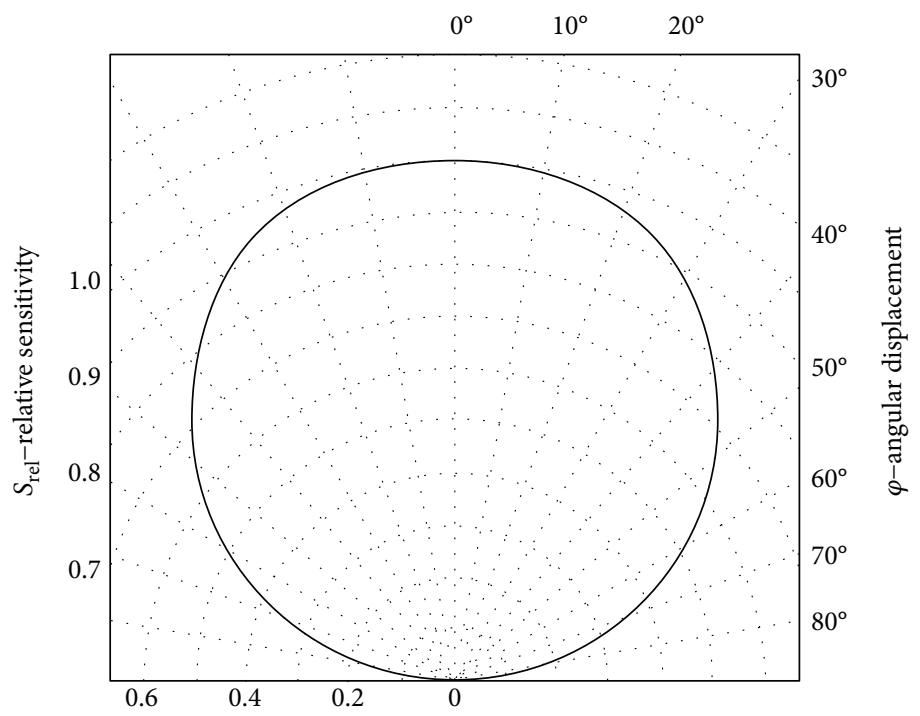

Figure 5: Relative radiant sensitivity and angular displacement of TEMT6000 [40].

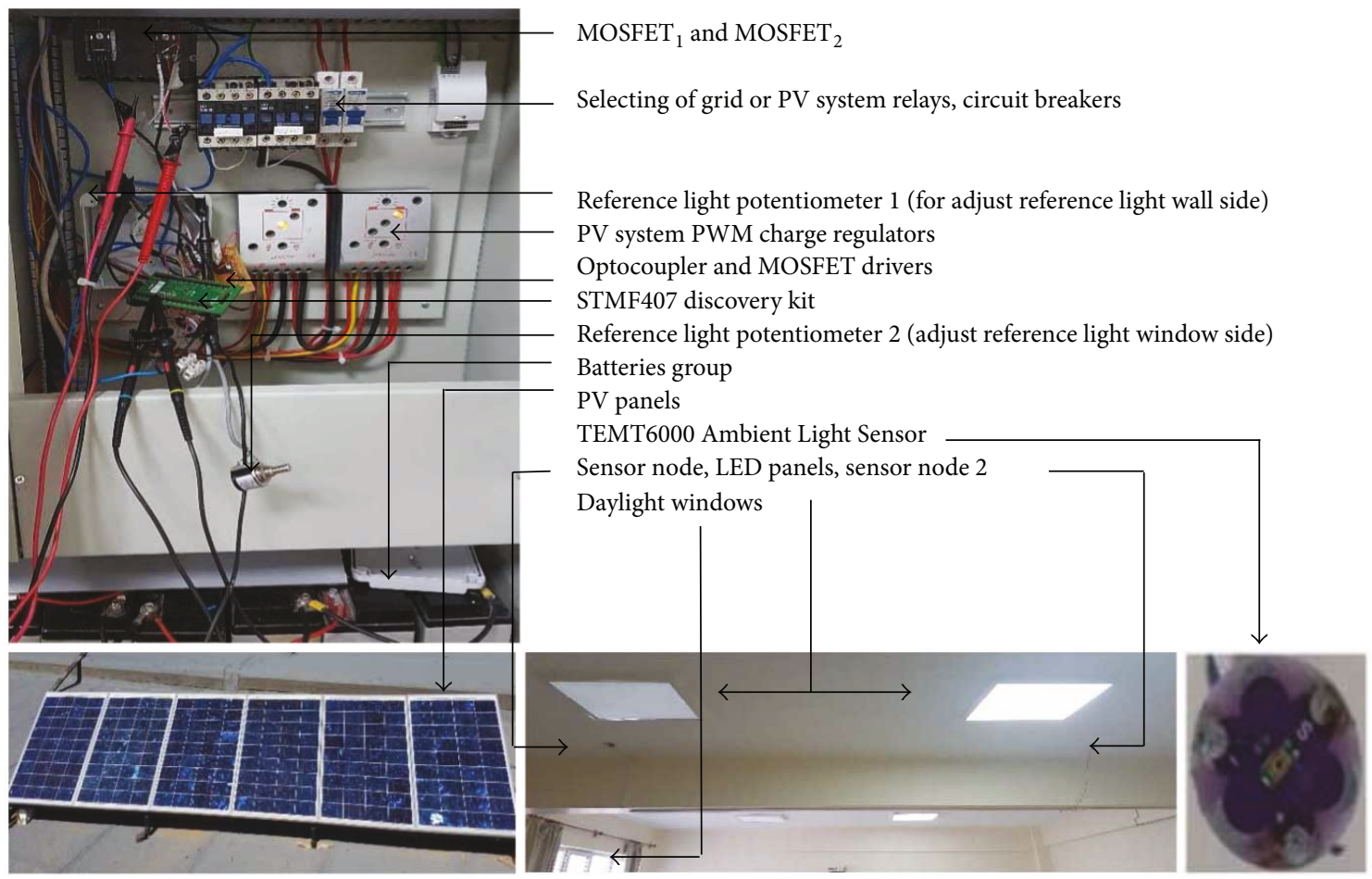

FIGURE 6: PV-based smart LED illuminating system.

is reached. With illumination control, a high level of energy saving has been reached.

2.2. Smart Control Algorithm of Central Sensor and Distributed Sensors LED Lighting System. In the proposed control algorithm, in the light of the voltage information based on the light received from the central or distributed ambient light sensors, it could be adjusted automatically which LED will work at which illumination lux value. The block diagrams and pseudocodes of the proposed algorithm can be seen in Figures 9 and 10, Pseudocodes 1 and 2, respectively. Here the $P_{s}$ information signifies the presence sensor's 0 or 1 information which is obtained on the human presence in the environment. The user-defined inputs to the control algorithm are room reference light (RRL), presence sensor time delay $\left(P_{\text {std }}\right)$ and its detection distance, increment $(I)$ value, sampling period, and hysteresis $(H)$. The light information and the active (logic 1) and passive (logic 0 ) states of the presence sensor signify the nonuser-definable entry information. This nonuser-definable input is the authentic 


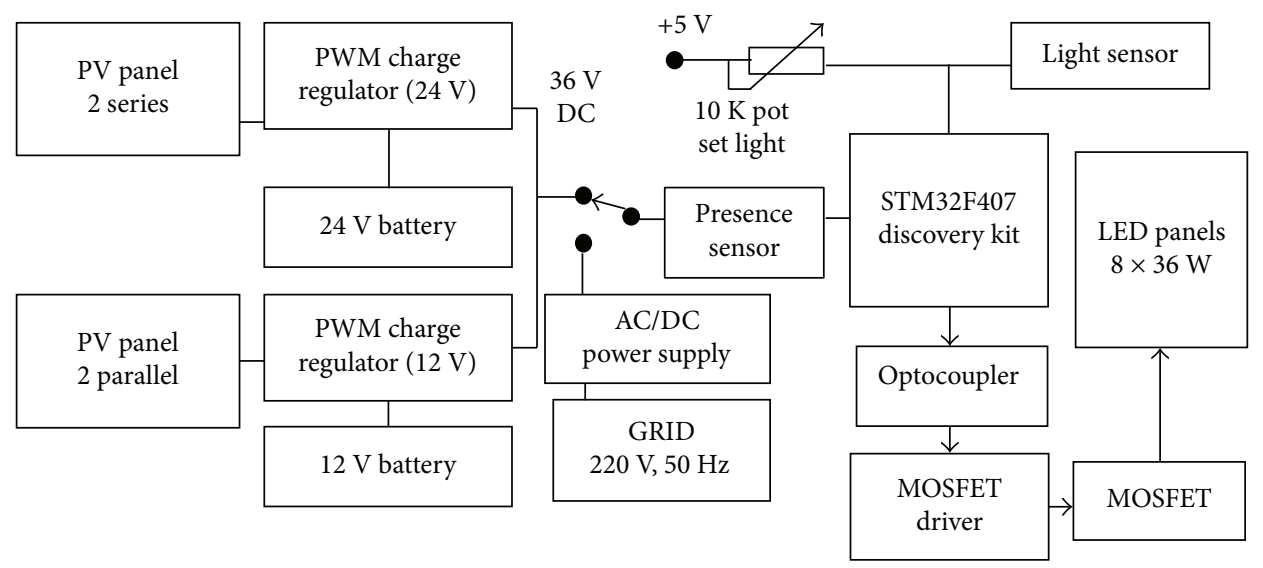

FIGURE 7: PV-based central sensor smart LED lighting system block chart.

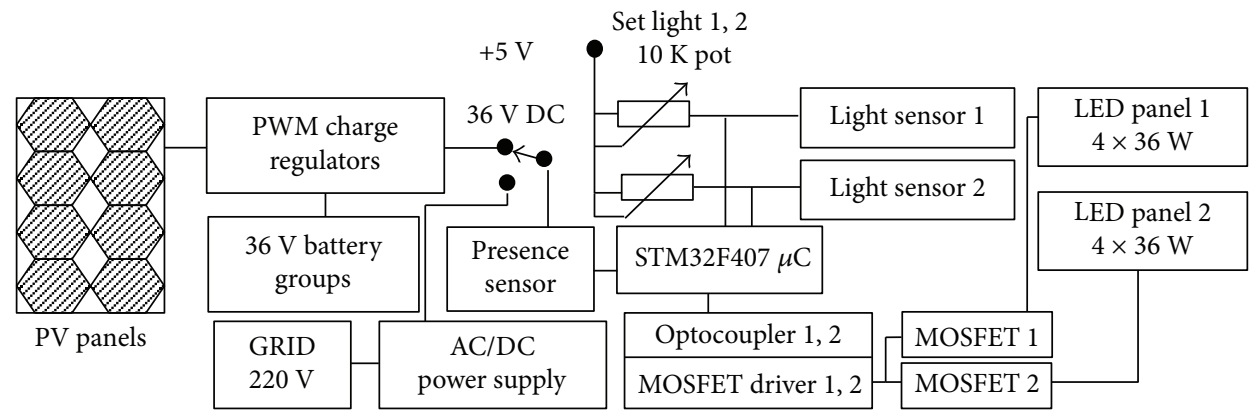

FIGURE 8: PV-based distributed sensor smart LED illuminating system block chart.

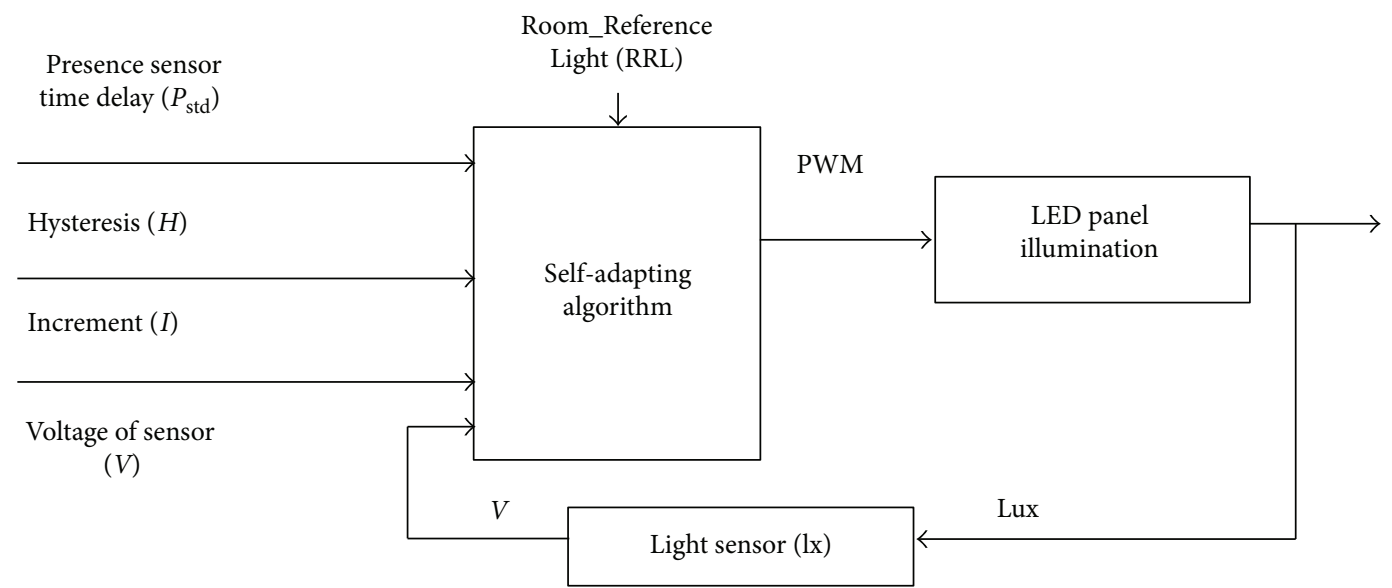

FIGURE 9: The proposed control algorithm central ambient light sensor smart LED system.

information received from the presence sensor. The hysteresis $(H)$ is a user-definable input that is determined at an accepted RRL interval of error 1 and error 2 . Value $H$ enables the illumination level to be at a certain interval and precludes unnecessary MOSFET switching losses by not applying duty cycles at minimum changes. Value increment $(I)$ signifies PWM outputs' increase or decrease coefficient. If the value
I in Figures 9 and 10 decreases, then the tracking of the MOSFET for regulating PWM will be slower and the time to reach reference value illumination will be longer. If the $I$ value increases, then the tracking will be faster. However, a large value $I$ will lead to overshoot. The value of $I$ is a userdefinable input. In the proposed approach, $500 \mathrm{~ms}$ was selected for the sampling period because it is a good 


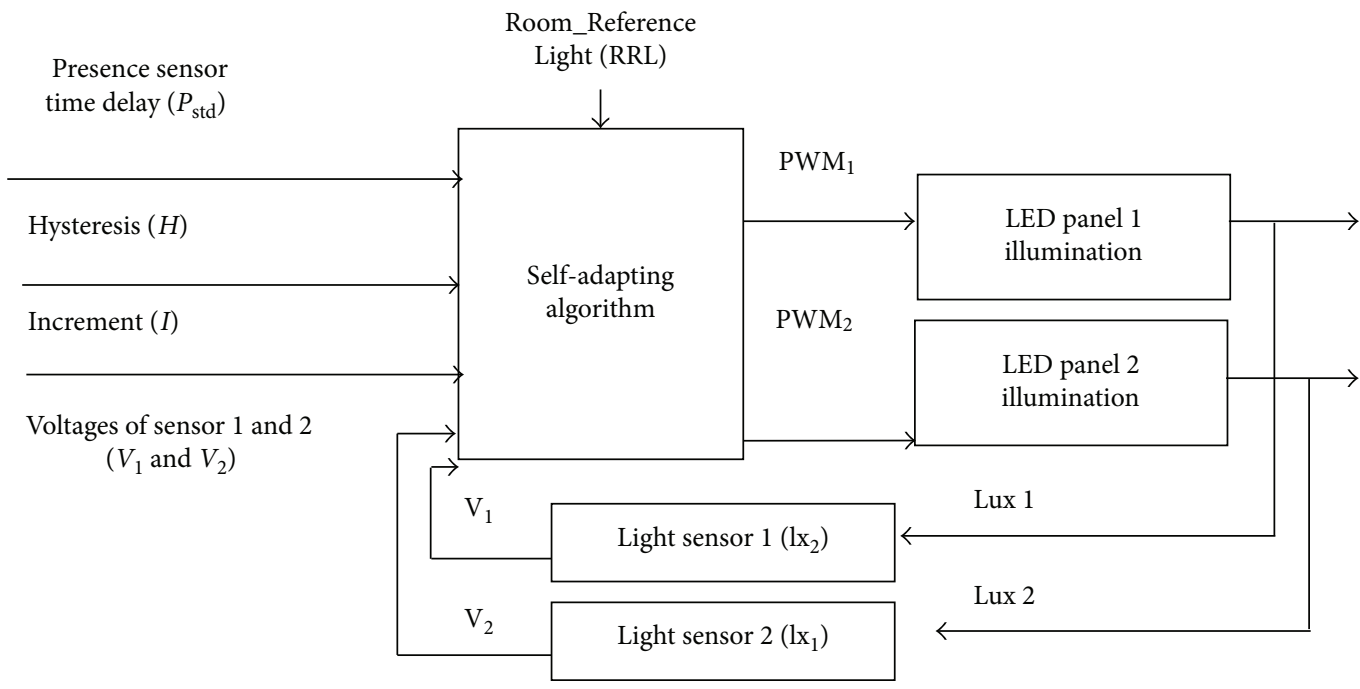

FIGURE 10: The proposed control algorithm-distributed ambient light sensor smart LED system.

trade-off between power and reactivity [14]. The aim of the control algorithm is to minimize error 1 and error 2, as calculated in (4), which should be kept in the hysteresis range. These error signals are calculated

Error 1, $2\left(t_{1}, t_{2}\right)=$ Room_Reference_Light - Measure_Light 1, 2.
The STM32F407 control card minimizes errors 1 and 2 by adjusting the duty cycle value and over the optocouplers composes the duty cycle $\left(\mathrm{PWM}_{1}\right.$ and $\left.\mathrm{PWM}_{2}\right)$ signals of MOSFET 1 and MOSFET 2. This way, the lighting level of the LED groups by the window and wall, which are connected to the MOSFETS' outputs, is controlled. The control card algorithm calculates the PWM values according to

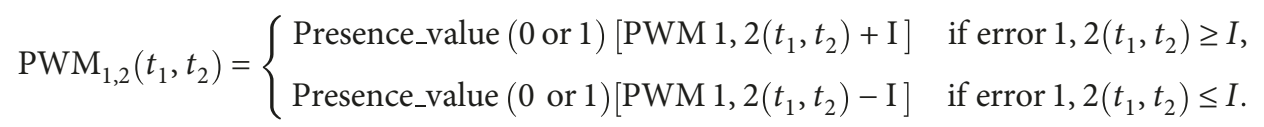

As it is seen in equation 5 , the logic 1 information, which is received from the presence sensor in line with the human presence, will start the PWM signals' creation. The error 1 and 2 values are kept at hysteresis level, and the increase and decrease of the PWM values are provided with value I. The LED panels in the central system are controlled by the MOSFET (Figure 7) PWM signal, and the LED panels in the distributed system are controlled by the $\mathrm{PWM}_{1,2}$ signals of MOSFET 1 and MOSFET 2 (Figure 8). The PWM values of the MOSFETs are produced by the control algorithm according to the reference illumination value. In this way, the LED panels give light at the desired illumination level. All the LED panels in the central sensor illumination system in Figure 9 are controlled by the values obtained from a single light sensor.

The sensor class shown in Figure 9 is located at the center of the ceiling. The information from the sensor is compared with the reference value of 300 lux, and the brightness of all the LED lamps is controlled by a single PWM signal.

In Figure 10, the first sensor gives the brightness information of the four LED lamps on the wall side and the second sensor gives the brightness information of the four LED lamps on the side of windows. The obtained information is compared with the reference value (300 lux), and two PWM signals are obtained. With these PWM signals, the first and second LED lamp groups are controlled separately. The pseudocode of the control algorithm for the central sensor smart lighting system is shown in Pseudocode 1.

When the codes in Pseudocode 1 are examined, the control algorithm starts with the presence sensor being active. With the PWM+I command, the light is increased, and with the PWM-I command, the light of all the lamps is decreased. The pseudocode of the control algorithm for the distributed sensor smart lighting system is shown in Pseudocode 2.

In the proposed smart system algorithm, the illumination level is tried to be kept at a certain value, and in case of minimal changes, the MOSFET PWM has not been regulated. At the same time, the LED lamp power has been regulated to the requested illumination value, which prevents unnecessary power loss and thus brings about an efficient lighting system.

In the distributed sensor LED lighting system, as shown in Pseudocode 2, MOSFET 1 driven by $\mathrm{PWM}_{1}$ signals controls LED panels by the wall side. On the other hand, MOS$\mathrm{FET}_{2}$ driven by $\mathrm{PWM}_{2}$ signals controls LED panels by the window side. 


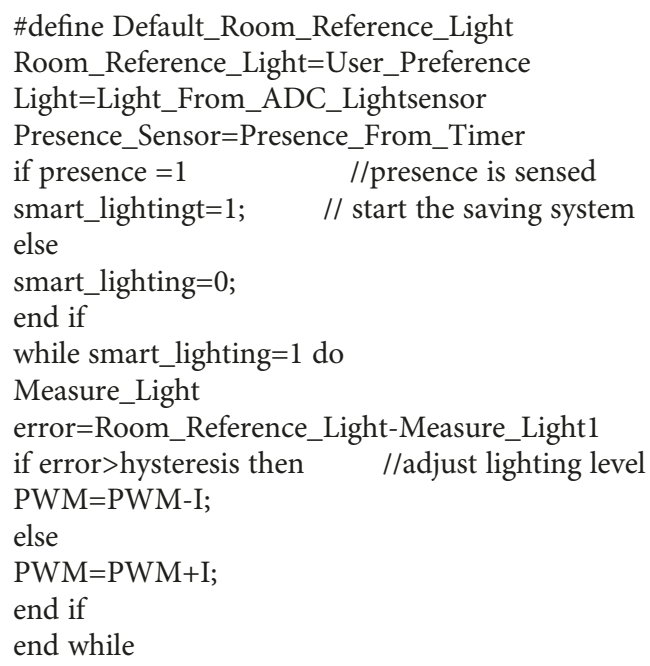

Pseudocode 1: Pseudocode of the control algorithm for the central sensor smart lighting system.

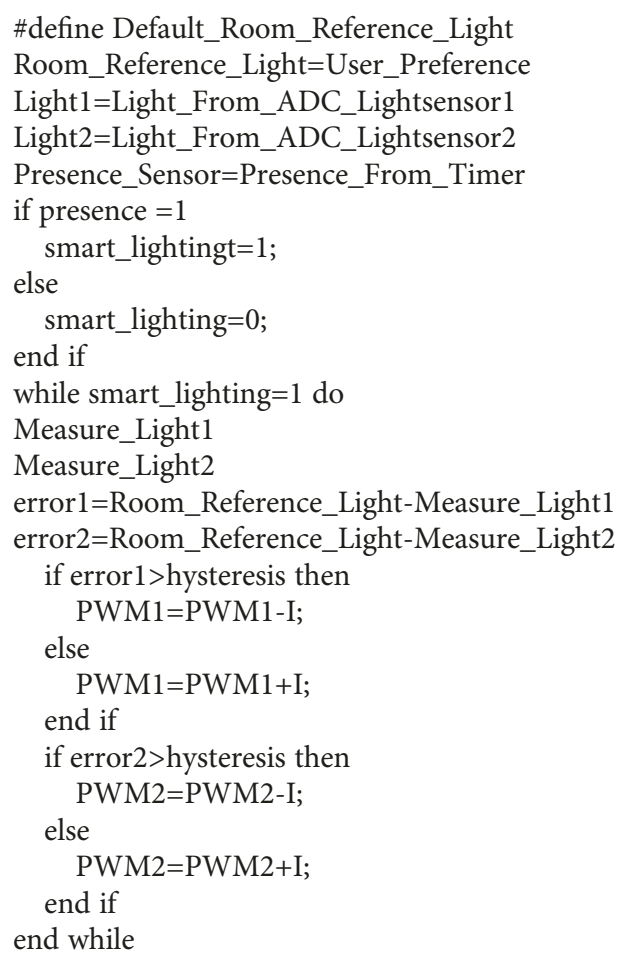

Pseudocode 2: Pseudocode of the control algorithm for the distributed sensor smart lighting system.

In this way, the LED panel groups by the wall and the window are managed by multiple ambient light sensors and distributed smart. Figure 11 illustrates the oscilloscope screenshot of the working system, as the impact of the outer environment lighting level by the window side is higher in comparison with that of the wall side; the LEDs by the window are used with less lighting level whereas the ones

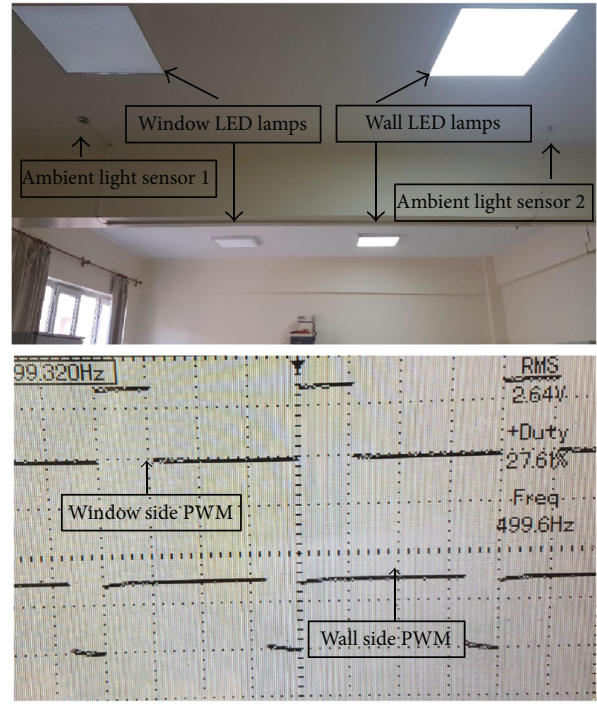

FIGURE 11: Distributed sensored LED control system working example and the oscilloscope image.

by the wall are used at a higher lighting level. As it is noticed from the oscilloscope screenshot, the rate of the window side duty cycle rate is 27.61 , but the wall side duty cycle rate is higher. Consequently, these results show that the lighting level of the groups of the LED lamps in the classroom has been efficiently controlled.

In Figure 11, it is targeted that the illumination level on the work surface is 300 lux. The contrast in LED lamps means that the illumination in the window area is higher than the light on the wall side. When the proposed distributed system balances this situation, the brightness levels of the lamps are as shown in Figure 11.

When the distributed sensored smart LED lighting system is controlled with a central single light sensor, it is seen that the LEDs by the window side work with a higher illumination value. Here, the positioning of the single light sensor can be seen in Figure 12.

\section{Results and Discussions}

3.1. The Comparison of the Proposed Central and Distributed Sensor Lighting System. The central and distributed sensor smart LED lighting system in the DC grid based on the PV system is performed, and the experiment outcomes were compared. Various experiments were performed on the developed smart LED lighting system powered by the DC grid to understand the performance under several environments in classroom conditions.

At the time of implemention of this experiment, the system has been working nonstop for two months and the values obtained belong to the date May 28. During the application, at the hours towards the evening it was noticed that the LED groups by the window side did not illuminate whereas those by the wall side illuminated. For the sunlight illumination measurement by the window side, a DT-1307 solar power meter was utilized (range: 0 to $1.999 \mathrm{~W} / \mathrm{m}^{2}$, 

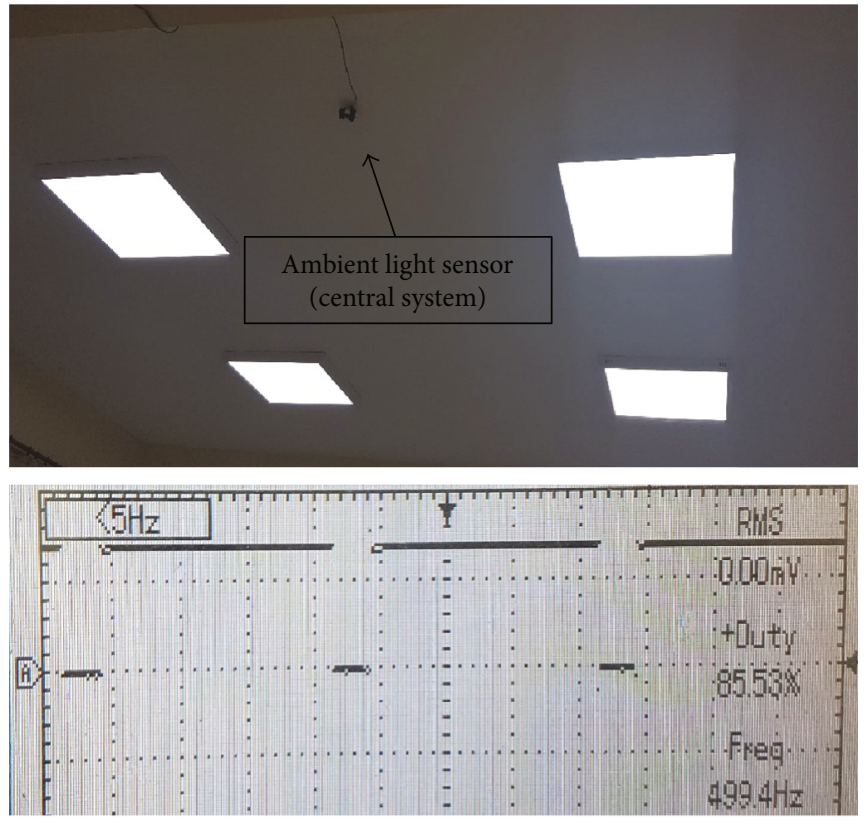

FIGURE 12: Central sensored LED control system working example image.

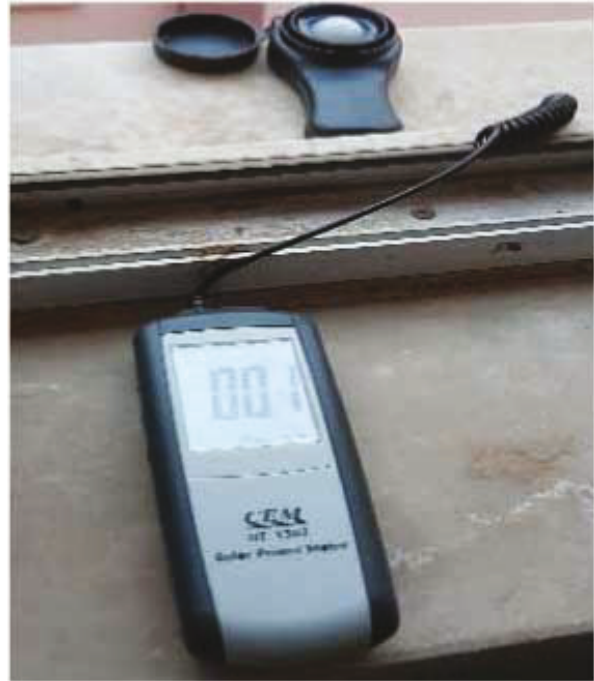

(a)

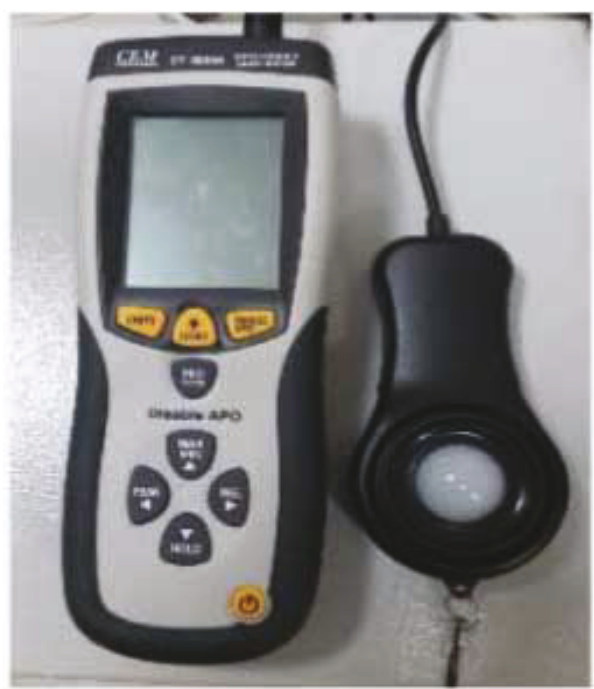

(b)

Figure 13: (a) Solar power meter $\left(\mathrm{W} / \mathrm{m}^{2}\right)$ and (b) light meter (lux).

resolution: $1 \mathrm{~W} / \mathrm{m}^{2}$, accuracy: $\pm 10 \mathrm{~W} / \mathrm{m}^{2}$ ), and for the classroom ambient lighting measurement, a DT-8809A professional light meter (max. range: 400,000 lux, resolution: 0.1 lux, accuracy: $\pm 5 \%$, spectral response: CIE photopic, photo detector: one silicon photodiode and spectral response filter) was utilized, as shown in Figure 13.

Depending on the light detected by the photocensors on the ceiling at night time, the workplace task illuminance value, which is 300 lux, has been acquired. In this way, the correlation between the illuminance levels on the ceiling has been provided.

The saved power values can be calculated by (6) [10], where $P_{\mathrm{c}}(t)$ and $P_{\mathrm{d}}(t)$ represent the output power of the proposed central and the proposed distributed sensor control lighting system, respectively [10].

$$
P_{\text {saved }}(t)=\Delta P=\int_{0}^{t} P_{c}(t) \mathrm{d} t-\int_{0}^{t} P_{\mathrm{d}}(t) \mathrm{d} t .
$$

In the experiment, three cases are conducted to compare the algorithm with both proposed central and distributed light sensors smart lighting systems.

Case 1. Towards evening, the time is 18:00 PM. While the solar power meter by the window shows $8 \mathrm{~W} / \mathrm{m}^{2}$ value, PWM outputs have the values for the window side at $0 \%$ 


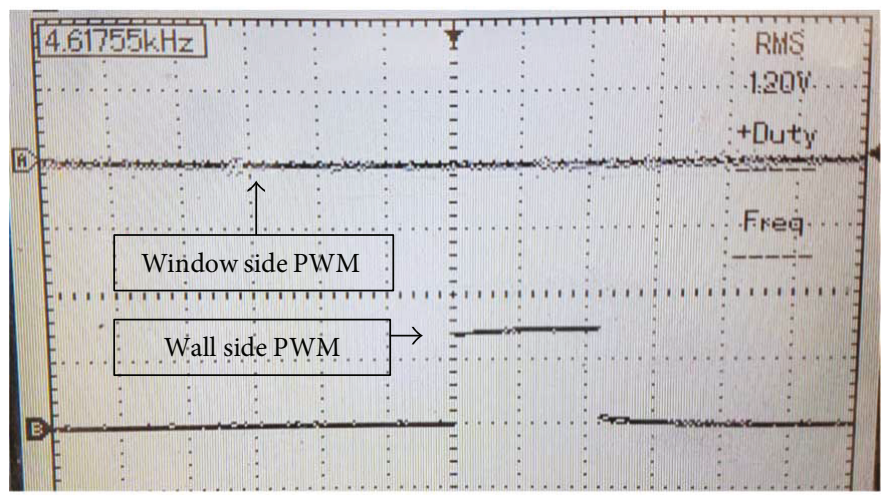

FIGURE 14: PWM signals of the proposed distributed lighting system: case 1 .

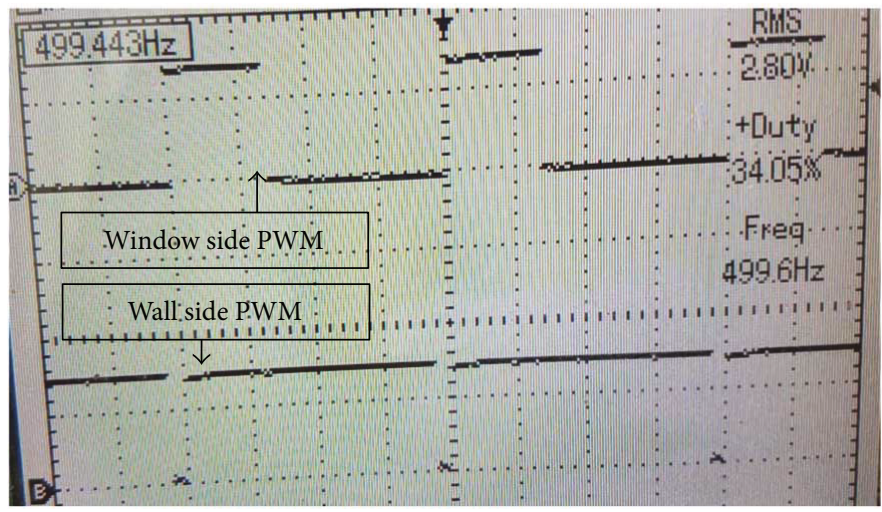

FIGURE 15: PWM signals of the proposed distributed lighting system: case 2.

and the wall side at $25 \%$. Namely, while the LEDs by the window side are illuminating, the LEDs by the wall side of the classroom are functioning at a $25 \%$ duty cycle level. When the control system has reached the reference lighting level, the total current value of the LEDs by the wall side is measured as $0.45 \mathrm{~A}$ and the current value of the LED lamps by the window side is measured as $0 \mathrm{~A}$. In this case, the power value of the proposed distributed ambient sensor smart LED lighting system is $36 \times 0.45=16.2 \mathrm{~W}$ and the power of the central ambient sensor smart LED lighting system is $32.4 \mathrm{~W}$. The difference is $32.4-16.2=16.2 \mathrm{~W}$. The oscilloscope screen of the PWM signals of the distributed sensored led lighting system for case 1 is given in Figure 14.

Case 2. The time is 19:30 PM. While the solar power meter shows $1.3 \mathrm{~W} / \mathrm{m}^{2}$, PWM outputs have the following values: for the LEDs by the window side $34.05 \%$ and for the LEDs by the wall side $90 \%$. When the control system has reached the reference lighting level, the total current value for the wall side LED panels is measured as $2.3 \mathrm{~A}$ and the current value for the window side LED panels is measured $0.6 \mathrm{~A}$. In this case, the power of the proposed distributed ambient sensor smart LED lighting system is $36(2.3+0.6)=104.4 \mathrm{~W}$ and the power of the central ambient sensor LED lighting system is $165.6 \mathrm{~W}$. The difference value is $165.6-104.4=61.2 \mathrm{~W}$.
The oscilloscope screen of PWM signals of the distributed sensor led lighting system for case 2 is given in Figure 15.

Case 3. Time is $19: 45 \mathrm{PM}$, the solar power meter shows $0.1 \mathrm{~W} / \mathrm{m}^{2}$ value, PWM outputs indicate the following values; for the LED panels by the window side $100 \%$ and for the LED panels by the wall side $90 \%$. When the control system has reached 304 lux reference lighting level, the total current value of the LED panels by the wall side is measured as $1.99 \mathrm{~A}$, the current value of the LED panels by the window side is $2 \mathrm{~A}$. In this case, while the power of the distributed sensor smart LED lighting system is $36(1.99+2)=143.64 \mathrm{~W}$, that of the central sensor smart LED lighting system's is $143.2 \mathrm{~W}$. The difference value between the two is $143.20-143.64=-0.44 \mathrm{~W}$. Here, it can be seen that the results are almost identical. The oscilloscope screen PWM signals of distributed sensor LED lighting system for case 3 is given in Figure 16.

All the three cases above were applied when it got dark and there was need for artificial illumination. At the earlier hours of the day, artificial illumination was not needed as the classroom had windows. Central and distributed light sensor artificial illumination was applied from 18:00 PM until 20:15 PM (the last hour before the classroom is closed). When all three cases are analyzed, it is seen that the proposed 


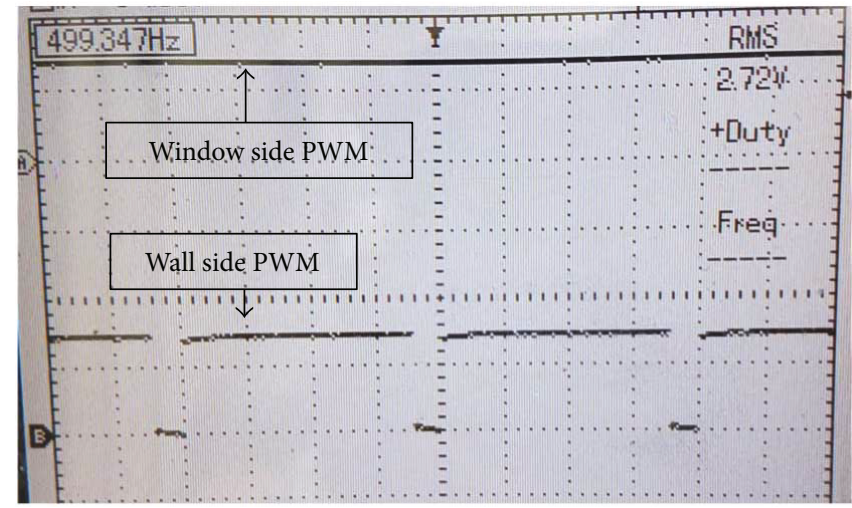

FIGURE 16: PWM signals of the proposed distributed lighting system: case 3.

TABle 2: The comparison of the proposed distributed sensors lighting with that of the central system.

\begin{tabular}{lcccc}
\hline Time & $\begin{array}{c}\text { Solar power } \\
\left(\mathrm{W} / \mathrm{m}^{2}\right)\end{array}$ & $\begin{array}{c}\text { The total consumed power in distributed } \\
\text { sensor smart LED lighting system }(\mathrm{W})\end{array}$ & $\begin{array}{c}\text { The total consumed power in central } \\
\text { sensor smart LED lighting system }(\mathrm{W})\end{array}$ & $\begin{array}{c}\Delta P(\text { power difference) } \\
(\mathrm{W})\end{array}$ \\
\hline $18: 00$ & 8 & 16.2 & 32.4 & 16.2 \\
$18: 15$ & 7.1 & 21.6 & 43.2 & 21.6 \\
$18: 30$ & 6.2 & 34.5 & 69.2 & 34.6 \\
$18: 45$ & 4.6 & 44.6 & 89.2 & 44.6 \\
$19: 00$ & 2.9 & 61.9 & 123.8 & 61.9 \\
$19: 15$ & 2.1 & 84.9 & 169.9 & 64.9 \\
$19: 30$ & 1.3 & 104.4 & 165.6 & -0.4 \\
$19: 45$ & 0.1 & 143.6 & 143.2 & 0 \\
$20: 00$ & 0 & 146.1 & 146.1 & 0 \\
$20: 15$ & 0 & 146.1 & 146.1 & $\Delta P_{\mathrm{C}}=112.8$ \\
$\Delta$ Mean & & $\Delta P_{\mathrm{D}}=80.3$ & &
\end{tabular}

distributed light sensor smart illumination has been successful in capturing the desired reference values, and when compared with the proposed central system, it is seen that the proposed distributed system provides more energy saving than the proposed central sensor smart LED lighting system.

In conventional fluorescent lamps, the facility of adjusting PWM is not possible. At the same time, conventional LED illuminating systems function with fixed power. In the proposed central sensored smart LED system, in line with voltage information received from the ambient light sensor stationed in the midpoint of the classroom close to the ceiling, the illumination level of all the LED panels is controlled. With the proposed distributed light sensor lighting system, wall and window LED panels are self-adapting and dimmed separately, and by bringing about an energy-saving situation, it has increased the efficiency of both illumination systems. The comparison of the proposed distributed light sensor smart LED lighting system with that of the central smart light sensor LED system is given in Table 2. By showing the powers consumed by the two systems and their power differences starting towards the evening time, the comparison of the two systems presents us a clearer understanding.

In Table 2, when the power change between the proposed central ambient sensor smart LED illumination system and the proposed distributed ambient light sensor LED illumination system is compared, it is seen that the highest value is 84.9 W. An efficiency calculation regarding Table 2 can be made as follows:

$$
\eta_{\text {ef ficiency }}=\frac{\Delta P_{\mathrm{C}}-\Delta P_{\mathrm{D}}}{\Delta P_{\mathrm{C}}}=\frac{112.8-80.4}{112.8} \times 100=\% 28.7 .
$$

It is seen that the proposed distributed ambient light sensor LED lighting system is $28.7 \%$ more efficient than the proposed central ambient light sensor. The LED lighting system works successfully at the universally determined ambient necessity illumination values. In spring and summer seasons, the use of LED panels and distributed light sensors or central light sensor smart LED lighting system is on the decrease, but in the other seasons its use is higher. The month when the measurement took place is May, which belongs to spring time.

3.2. Cost Analysis. The total setup cost of the central and distributed ambient light sensor smart LED lighting system controller is calculated and listed in Table 3. 
TABLE 3: Cost analysis of the developed energy-saving controller.

\begin{tabular}{lccc}
\hline Item & Unit cost (USD) & $\begin{array}{c}\text { Central/distributed } \\
\text { system number }\end{array}$ & $\begin{array}{c}\text { Total cost (USD) } \\
\text { central/distributed system }\end{array}$ \\
\hline STM32F407 discovery kit & 25.6 & $1 / 1$ & $25.6 / 25.6$ \\
IRFP250 MOSFET & 1.4 & $1 / 2$ & $1.4 / 2.8$ \\
10 K multiturn pot & 4 & $1 / 2$ & $4 / 8$ \\
Optocoupler & 0.2 & $1 / 2$ & $0.2 / 0.4$ \\
5 V power switch regulator & 11.2 & $1 / 1$ & $11.2 / 11.2$ \\
MOSFET driver & 1.9 & $1 / 2$ & $1.9 / 3.8$ \\
TEMT6000 Ambient Light Sensor & 5.3 & $1 / 2$ & $5.3 / 10.6$ \\
Resistor & 0.06 & $1 / 2$ & $0.06 / 0.1$ \\
100 nF capacitor & 0.07 & $1 / 2$ & $0.07 / 0.1$ \\
MOSFET cooler & 2.1 & $1 / 2$ & $2.1 / 4.3$ \\
PCB & 0.4 & $1 / 1$ & $0.4 / 0.4$ \\
Proposed central/distributed sensor LED lighting system costs & & $52.2 / 67.3$ & \\
\hline
\end{tabular}

TABLE 4: Results of economic analysis for the central and distributed smart led lighting system.

\begin{tabular}{|c|c|c|c|c|c|}
\hline System & $\begin{array}{l}\text { kWh unit cost } \\
\text { (USD) }[44]\end{array}$ & $\begin{array}{c}\text { Average daily } \\
\text { consumption (kWh) }\end{array}$ & $\begin{array}{c}\text { Average total daily } \\
\text { consumption for } 5 \text { hours }\end{array}$ & $\begin{array}{c}\text { Average monthly } \\
\text { consumption }(\mathrm{kWh})\end{array}$ & $\begin{array}{c}\text { Total cost } \\
\text { (USD) }\end{array}$ \\
\hline $\begin{array}{l}\text { The central sensor smart } \\
\text { LED lighting }\end{array}$ & 0.12 & 112.8 & 564 & 16.92 & 1.92 \\
\hline $\begin{array}{l}\text { The distributed sensor } \\
\text { LED lighting }\end{array}$ & 0.12 & 80.3 & 401.5 & 12 & 1.44 \\
\hline The normal LED lighting & 0.12 & 288 & 1440 & 43.2 & 5.18 \\
\hline
\end{tabular}

The total costs of the proposed central and distributed system are 52.2 and 67.3 USD, respectively. The system is flexible, meaning it can be expanded.

A monetary payback period for the proposed centraldistributed light sensor LED lighting and the normal LED lighting systems is made, as shown in Tables 2 and 4 .

When Table 4 is examined, it is seen that the $288 \mathrm{~W}$ LED panel-installed power capacity of the central illumination system has an average monthly consumption of $16.92 \mathrm{kWh}$, and its cost is 1.92 USD. It shows that there is a total cost difference of $5.18-1.92=3.26$ USD between the central smart LED lighting and the normal LED lighting systems. In Table 4, if the total cost amount for the central smart LED lighting system is divided by the value found, the simple monetary payback period is calculated as 52.2/ $3.26=16$ months.

3.3. Visual Comfort. The daylight source can be measured, but it is uncontrollable. Color, distribution, and other features of daylight are highly variable, and the speed of this variability is coincident with many components. This is a characteristic of human nature. In Figure 17, there is a building which is 6 meters south of the working class and there is a light shelf over the roof of the class building which provides indirect daylight diffusion which is one of the best types for both comfort and work. As seen in Figure 17, a daylight of the room reduces energy consumption. The sensors are placed on the ceiling in such a way

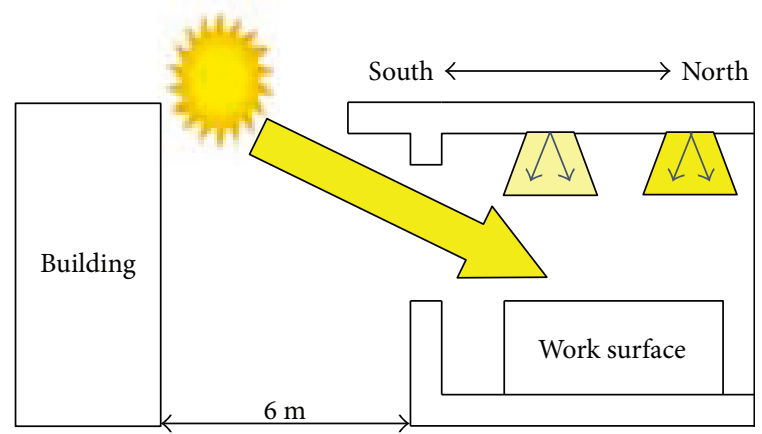

FIgURE 17: The position of the building and artificial lighting controlled with daylight availability.

that they are not affected by direct daylight and the LED lamps are light. A reference 300 lux was targeted for the working surface illumination value.

The color rendering index (CRI) and color temperature (kelvin) are important parameters in achieving visual comfort. The scale range of the color rendering index is $0-100$; the natural light has a value of $100 \mathrm{CRI}$, and it is recommended that the CRI value should be higher than 80 . The LED lamps selected for illumination of the class have a color rendering index which is greater than 80 , and the color temperature of LED is $4000 \mathrm{~K}$. Visual comfort zones based on color temperature and room illumination level are shown in Figure 18. To achieve better user satisfaction 


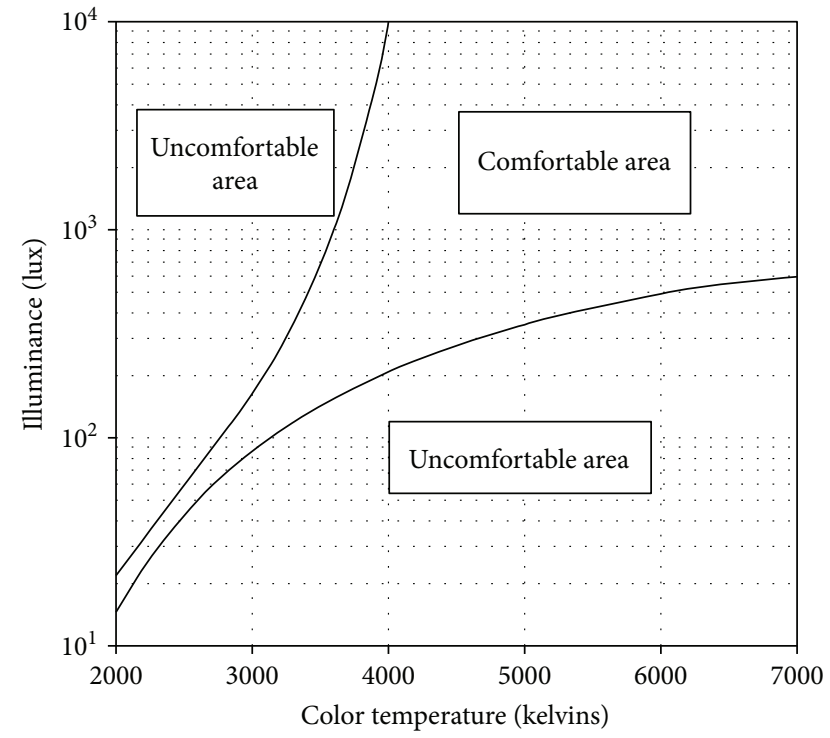

FIgURe 18: Comfort zone of the Kruithof curve [45].

and according to the Kruithof curve given in Figure 18, the intersection of the reference value of the illumination and color temperature of the LED lamp lays in the visual comfort zone.

\section{Conclusion}

Natural lighting reduces energy consumption of artificial lighting such as LED or fluorescent lighting, and it provides a healthy and comfortable environment. As is known, not much research comparing the distributed and central sensor smart LED lighting systems with respect to energy efficiency has been carried out. In this study, a PV system set up on the building meets the energy demand of the DC grid LED panel structure whose illumination level has been controlled by the proposed self-adapting algorithm based on the information taken from distributed ambient light sensors. The system is composed of the presence sensor, ambient light sensors, PV system, control card, and battery elements. The use of the ambient light sensors and the presence sensor in combination with the user preferences allows the central or the distributed ambient sensor smart to save energy and thus reduce the light intensity. From the measurement taken two hours before sunset, the distributed system energy consumption was $16.2 \mathrm{~W}$ while that of the central sensor's stood at $32.4 \mathrm{~W}$. One hour before the sunset, these values stood at $61.92 \mathrm{~W}$ and $123.84 \mathrm{~W}$, respectively. When the proposed distributed ambient light sensors and the proposed central ambient light sensor smart LED lighting systems are compared, it is seen that the proposed distributed ambient light sensor smart LED lighting system comes with $28.762 \%$ more efficiency. At the same time, both proposed systems have a low consumption rate and building integrated photovoltaic (BIPV) basis which offers an environmentally friendly approach.

\section{Conflicts of Interest}

The author declares that there is no conflict of interest regarding the publication of this paper.

\section{References}

[1] A. M. Vural, "Contribution of high voltage direct current transmission systems to inter-area oscillation damping: a review," Renewable and Sustainable Energy Reviews, vol. 57, pp. 892-915, 2016.

[2] L. Shen, B. He, L. Jiao, X. Song, and X. Zhang, "Research on the development of main policy instruments for improving building energy-efficiency," Journal of Cleaner Production, vol. 112, Part 2, pp. 1789-1803, 2016.

[3] M. S. Hossain, N. A. Madlool, N. A. Rahim, J. Selvaraj, A. K. Pandey, and A. F. Khan, "Role of smart grid in renewable energy: an overview," Renewable and Sustainable Energy Reviews, vol. 60, pp. 1168-1184, 2016.

[4] R. Smale, M. Hartley, C. Hepburn, J. Ward, and M. Grubb, "The impact of $\mathrm{CO}_{2}$ emissions trading on firm profits and market prices," Climate Policy, vol. 6, no. 1, pp. 31-48, 2006.

[5] S.-H. Kim, I.-T. Kim, A.-S. Choi, and M. K. Sung, "Evaluation of optimized PV power generation and electrical lighting energy savings from the PV blind-integrated daylight responsive dimming system using LED lighting," Solar Energy, vol. 107, pp. 746-757, 2014.

[6] S.-H. Yoo, "Simulation for an optimal application of BIPV through parameter variation," Solar Energy, vol. 85, no. 7, pp. 1291-1301, 2011.

[7] M. D. Archer and R. Hill, Clean electricity from photovoltaics, Imperial College Press, London, 2001.

[8] B. Celik, E. Karatepe, S. Silvestre, N. Gokmen, and A. Chouder, "Analysis of spatial fixed PV arrays configurations to maximize energy harvesting in BIPV applications," Renewable Energy, vol. 75, pp. 534-540, 2015.

[9] D. Tran and Y. K. Tan, "Sensorless illumination control of a networked LED-lighting system using feedforward neural network," IEEE Transactions on Industrial Electronics, vol. 61, no. 4, pp. 2113-2121, 2014.

[10] I. Chew, V. Kalavally, N. W. Oo, and J. Parkkinen, "Design of an energy-saving controller for an intelligent LED lighting system," Energy and Buildings, vol. 120, pp. 1-9, 2016.

[11] I. G. Mason, S. C. Page, and A. G. Williamson, "A 100\% renewable electricity generation system for New Zealand utilising hydro, wind, geothermal and biomass resources," Energy Policy, vol. 38, no. 8, pp. 3973-3984, 2010.

[12] P. Mallet, P.-O. Granstrom, P. Hallberg, G. Lorenz, and P. Mandatova, "Power to the people!: European perspectives on the future of electric distribution," IEEE Power and Energy Magazine, vol. 12, no. 2, pp. 51-64, 2014.

[13] C. K. Lee, S. Li, and S. Y. Hui, “A design methodology for smart LED lighting systems powered by weakly regulated renewable power grids," IEEE Transactions on Smart Grid, vol. 2, no. 3, pp. 548-554, 2011.

[14] M. Magno, T. Polonelli, L. Benini, and E. Popovici, "A low cost, highly scalable wireless sensor network solution to achieve smart LED light control for green buildings," IEEE Sensors Journal, vol. 15, no. 5, pp. 2963-2973, 2015.

[15] H.-J. Chiu, Y.-K. Lo, J.-T. Chen, S.-J. Cheng, C.-Y. Lin, and S.-C. Mou, "A high-efficiency dimmable LED driver for low- 
power lighting applications," IEEE Transactions on Industrial Electronics, vol. 57, no. 2, pp. 735-743, 2010.

[16] M. Arias, D. G. Lamar, J. Sebastian, D. Balocco, and A. A. Diallo, "High-efficiency LED driver without electrolytic capacitor for street lighting," IEEE Transactions on Industry Applications, vol. 49, no. 1, pp. 127-137, 2013.

[17] S. Li, H. Chen, S.-C. Tan, S. Y. R. Hui, and E. Waffenschmidt, "Power flow analysis and critical design issues of retrofit lightemitting diode (LED) light bulb," IEEE Transactions on Power Electronics, vol. 30, no. 7, pp. 3830-3840, 2015.

[18] D. H. W. Li, K. L. Cheung, S. L. Wong, and T. N. T. Lam, "An analysis of energy-efficient light fittings and lighting controls," Applied Energy, vol. 87, no. 2, pp. 558$567,2010$.

[19] Y. K. Tan, T. P. Huynh, and Z. Wang, "Smart personal sensor network control for energy saving in DC grid powered LED lighting system," IEEE Transactions on Smart Grid, vol. 4, no. 2, pp. 669-676, 2013.

[20] A. Pandharipande and D. Caicedo, "Smart indoor lighting systems with luminaire-based sensing: a review of lighting control approaches," Energy and Buildings, vol. 104, pp. 369$377,2015$.

[21] G. Lowry, "Energy saving claims for lighting controls in commercial buildings," Energy and Buildings, vol. 133, pp. 489-497, 2016.

[22] F. Rubinstein, G. Ward, and R. Verderber, "Improving the performance of photo-electrically controlled lighting systems," Journal of the Illuminating Engineering Society, vol. 18, no. 1, pp. 70-94, 1989.

[23] M. T. Koroglu and K. M. Passino, "Illumination balancing algorithm for smart lights," IEEE Transactions on Control Systems Technology, vol. 22, no. 2, pp. 557-567, 2014.

[24] M. Fischer, K. Wu, and P. Agathoklis, "Intelligent illumination model-based lighting control," in 2012 32nd International Conference on Distributed Computing Systems Workshops, pp. 245-249, Macau, China, June 2012.

[25] G. Boscarino and M. Moallem, "Daylighting control and simulation for LED-based energy-efficient lighting systems," IEEE Transactions on Industrial Informatics, vol. 12, no. 1, pp. 301-309, 2016.

[26] F. Rubinstein, "Photoelectric control of equi-illumination lighting systems," Energy and Buildings, vol. 6, no. 2, pp. 141-150, 1984.

[27] A. Peruffo, A. Pandharipande, D. Caicedo, and L. Schenato, "Lighting control with distributed wireless sensing and actuation for daylight and occupancy adaptation," Energy and Buildings, vol. 97, pp. 13-20, 2015.

[28] D. Caicedo and A. Pandharipande, "Distributed illumination control with local sensing and actuation in networked lighting systems," IEEE Sensors Journal, vol. 13, no. 3, pp. 10921104, 2013.

[29] S. H. Lee and J. K. Kwon, "Distributed dimming control for LED lighting," Optics Express, vol. 21, Supplement 6, pp. A917-A932, 2013.

[30] A. Fernandez-Montes, L. Gonzalez-Abril, J. Ortega, and F. Morente, "A study on saving energy in artificial lighting by making smart use of wireless sensor networks and actuators," IEEE Network, vol. 23, no. 6, pp. 16-20, 2009.

[31] J. Vanus, T. Novak, J. Koziorek, J. Konecny, and R. Hrbac, "The proposal model of energy savings of lighting systems in the smart home care," in 12th IFAC conference on programmable devices and embedded systems, Czech Republic, September 2013.

[32] J. Liu, W. Zhang, X. Chu, and Y. Liu, "Fuzzy logic controller for energy savings in a smart LED lighting system considering lighting comfort and daylight," Energy and Buildings, vol. 127, pp. 95-104, 2016.

[33] İ. Kiyak, B. Oral, and V. Topuz, "Smart indoor LED lighting design powered by hybrid renewable energy systems," Energy and Buildings, vol. 148, pp. 342-347, 2017.

[34] M. A. Özçelik, "Light sensor control for energy saving in DC grid smart LED lighting system based on PV system," Journal of Optoelectronics and Advanced Materials, vol. 18, no. 5-6, pp. 468-474, 2016.

[35] M. A. Özçelik, “The design and implementation of PV-based intelligent distributed sensor LED lighting in daylight exposed room environment," Sustainable Computing: Informatics and Systems, vol. 13, pp. 61-69, 2017.

[36] D. K. Gupta, M. Barink, and M. Langelaar, "CPV solar cell modeling and metallization optimization," Solar Energy, vol. 159, pp. 868-881, 2018.

[37] "EN 12464-1, light and lighting-lighting of work places part 1: indoor workplaces," EN Standard. September 2017, https:// www.en-standard.eu/csn-en-12464-1-light-and-lighting-lightingof-work-places-part-1-indoor-work-places/.

[38] “LED catalogue," Pelsan. December 2016, http://www.pelsan .com.tr/en-US/catalogues/52212.

[39] J. D. Jennings, F. M. Rubinstein, D. DiBartolomeo, and S. L. Blanc, "Comparison of control options in private offices in an advanced lighting controls testbed," Journal of the Illuminating Engineering Society, vol. 29, no. 2, pp. 39$60,2000$.

[40] “TEMT6000 ambient light sensor," Vishay. August 2017, https://www.vishay.com/docs/81579/temt6000.pdf.

[41] A.-S. Choi, K.-D. Song, and Y.-S. Kim, “The characteristics of photosensors and electronic dimming ballasts in daylight responsive dimming systems," Building and Environment, vol. 40, no. 1, pp. 39-50, 2005.

[42] S. Ranasinghe and R. Mistrick, "A study of photosensor configuration and performance in a daylighted classroom space," Journal of the Illuminating Engineering Society, vol. 32, no. 2, pp. 3-20, 2003.

[43] L. Doulos, A. Tsangrassoulis, and F. V. Topalis, "Multi-criteria decision analysis to select the optimum position and proper field of view of a photosensor," Energy Conversion and Management, vol. 86, pp. 1069-1077, 2014.

[44] "Guide for electricity tariff regulations in Turkey, 2016," EMRA. December 2016, http://www.emra.org.tr/en/home.

[45] S. Afshari, S. Mishra, A. Julius, F. Lizarralde, J. D. Wason, and J. T. Wen, "Modeling and control of color tunable lighting systems," Energy and Buildings, vol. 68, Part A, pp. 242-253, 2014. 

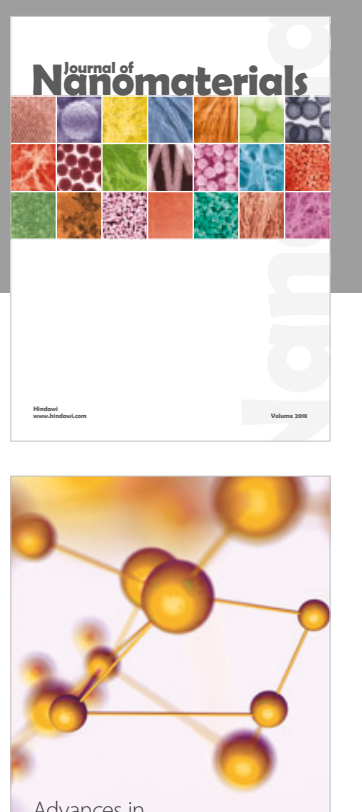

Physical Chemistry
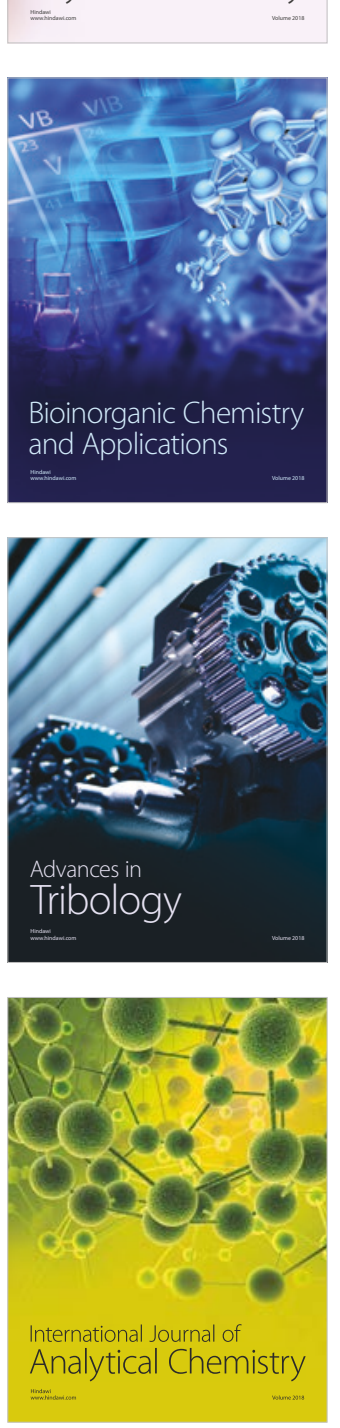

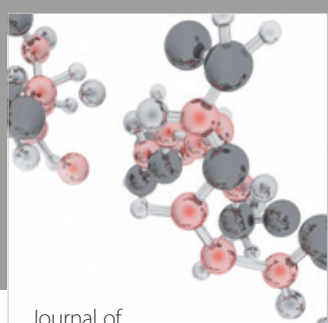

Analytical Methods

in Chemistry

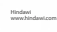

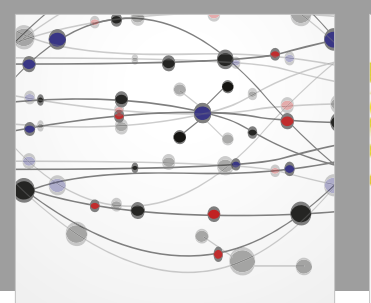

The Scientific World Journal

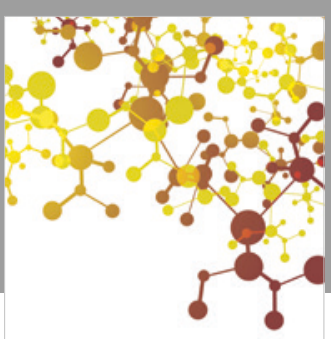

Journal of

Applied Chemistry
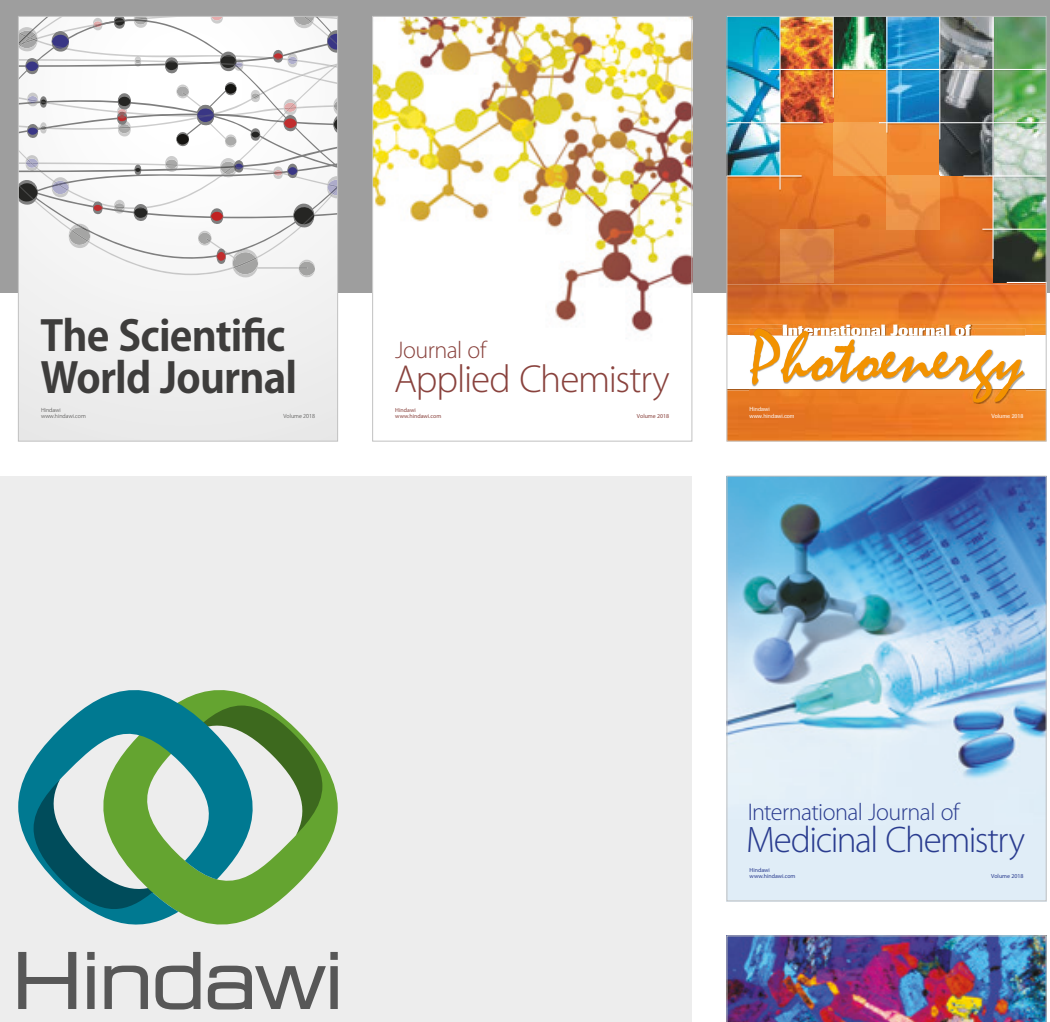

Submit your manuscripts at

www.hindawi.com
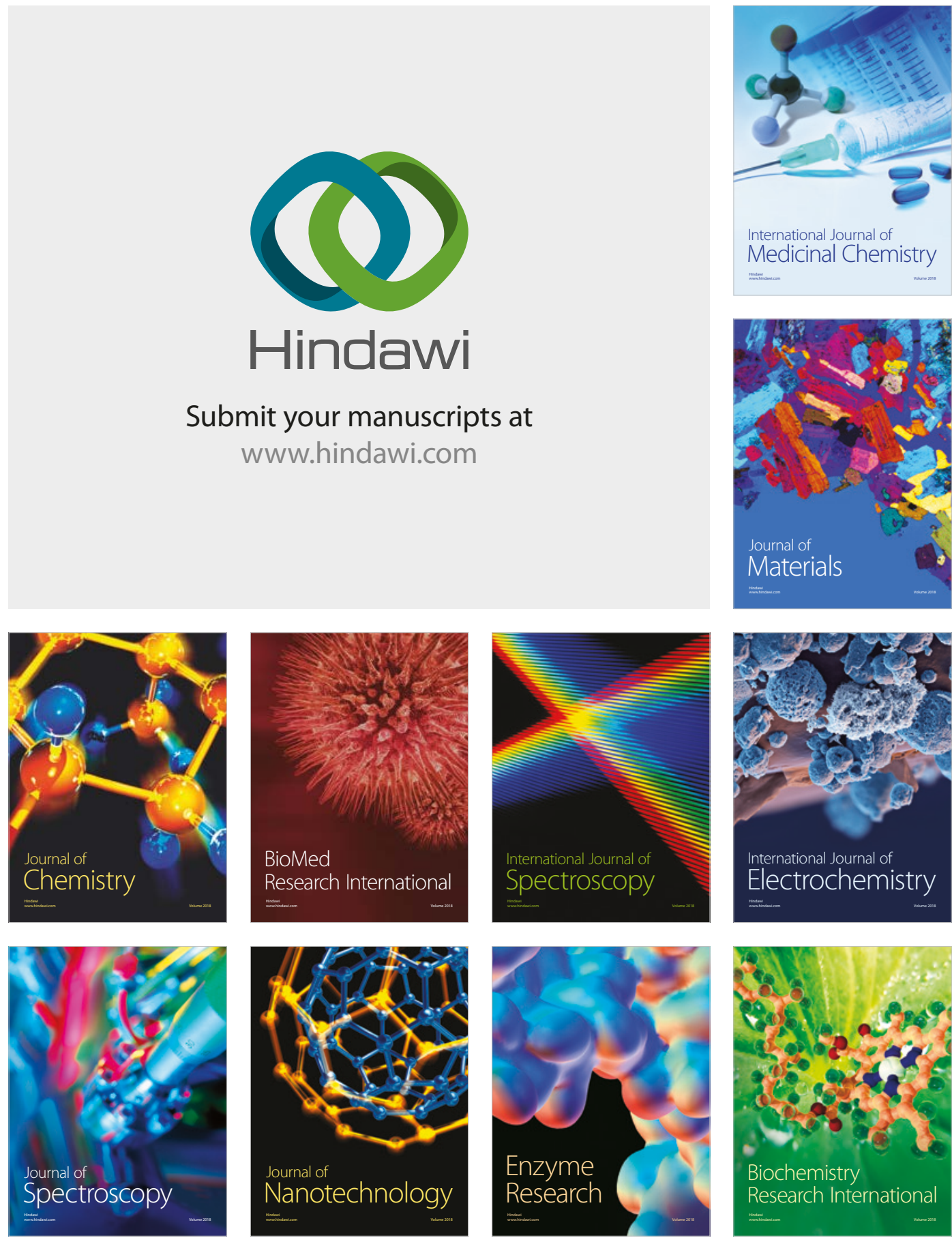
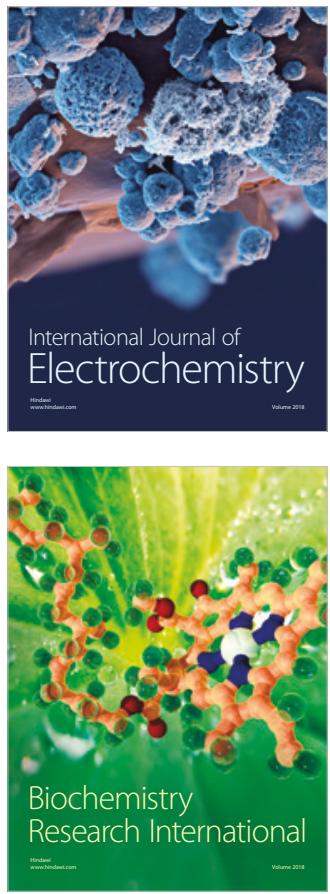